\title{
Iron redistribution in a zirconium alloy after neutron and proton irradiation studied by energy-dispersive X-ray spectroscopy (EDX) using an aberration-corrected (scanning) transmission electron microscope
}

\section{DOI:}

10.1016/j.jnucmat.2014.08.034

Document Version

Accepted author manuscript

Link to publication record in Manchester Research Explorer

\section{Citation for published version (APA):}

Francis, E., Harte, A., Frankel, P., Haigh, SJ., Jädernäs, D., Romero, J., Hallstadius, L., \& Preuss, M. (2014). Iron redistribution in a zirconium alloy after neutron and proton irradiation studied by energy-dispersive $\mathrm{X}$-ray spectroscopy (EDX) using an aberration-corrected (scanning) transmission electron microscope. Journal of Nuclear Materials, 454(1-3), 387-397. https://doi.org/10.1016/j.jnucmat.2014.08.034

\section{Published in:}

Journal of Nuclear Materials

\section{Citing this paper}

Please note that where the full-text provided on Manchester Research Explorer is the Author Accepted Manuscript or Proof version this may differ from the final Published version. If citing, it is advised that you check and use the publisher's definitive version.

\section{General rights}

Copyright and moral rights for the publications made accessible in the Research Explorer are retained by the authors and/or other copyright owners and it is a condition of accessing publications that users recognise and abide by the legal requirements associated with these rights.

\section{Takedown policy}

If you believe that this document breaches copyright please refer to the University of Manchester's Takedown Procedures [http://man.ac.uk/04Y6Bo] or contact uml.scholarlycommunications@manchester.ac.uk providing relevant details, so we can investigate your claim.

\section{OPEN ACCESS}


Iron redistribution in a zirconium alloy after neutron and proton irradiation studied by energy-dispersive $X$-ray spectroscopy (EDX) using an aberration-corrected (scanning) transmission electron microscope

E.M. Francis ${ }^{1}$, A. Harte ${ }^{1}$, P. Frankel ${ }^{1}$, S.J. Haigh ${ }^{1}$, D. Jädernäs ${ }^{2}$, J. Romero ${ }^{3}$, L. Hallstadius $^{4}$, M.Preuss ${ }^{1}$,

${ }^{1}$ The University of Manchester, Manchester Materials Science Centre, Grosvenor Street, Manchester, M13 9PL, United Kingdom

${ }^{2}$ Studsvik Nuklear AB, SE 61182 Nyköoing, Sweden

${ }^{3}$ Westinghouse Electric Company, Columbia, SC, United States

${ }^{4}$ Westinghouse Electric Sweden AB, SE-72163 Västerås, Sweden

Corresponding author: Dr. Elisabeth Francis

Email: Elisabeth.Francis@manchester.ac.uk

Phone: +441613063591

Postal address: The University of Manchester

School of Materials

Manchester

M13 9PL

United Kingdom

Email addresses of the co-authors:

Allan Harte allan.harte@postgrad.manchester.ac.uk

Philipp Frankel philipp.frankel@manchester.ac.uk

Sarah Haigh Sarah.Haigh@manchester.ac.uk

Daniel Jädernäs daniel.jadernas@studsvik.se

Javier Romero romeroje@westinghouse.com

Lars Hallstadius hallstlg@westinghouse.com

Michael Preuss Michael.preuss@manchester.ac.uk 


\begin{abstract}
Zirconium alloys used as cladding materials in nuclear reactors can exhibit accelerated irradiation induced growth, often termed linear growth, after sustained neutron irradiation. This phenomenon has been linked to the formation of $<\mathrm{c}>$-component dislocation loops and to the concentration of interstitial solute atoms. It is well documented for the Zircaloys that Fe dissolves from second phase particles (SPPs) during irradiation thus increasing the interstitial solute concentration in the matrix. However, no progress has yet been made into understanding whether a similar process occurs for the newer ZIRLO $^{\text {TM }}$ alloys. We aim to overcome this shortcoming here by studying compositional changes in second phase particles in Low Tin ZIRLO ${ }^{\text {TM }}$ after neutron and proton irradiation using energy dispersive X-ray (EDX) spectroscopy. Material irradiated to $18 \mathrm{dpa}$ (displacements per atom) using neutrons and to 2.3 and 7 dpa by protons was investigated. The results show that $\mathrm{Fe}$ is lost from $\mathrm{Zr}-\mathrm{Nb}$-Fe-SPPs during both neutron and proton irradiation. Prior to irradiation, $\mathrm{Fe}$ was detected at the interface of $\beta$-Nb-SPPs. This Fe enrichment is also dispersed during irradiation. Qualitatively, excellent agreement was found regarding the elemental redistribution processes observed after proton and neutron irradiation.
\end{abstract}

\title{
1. Introduction
}

Zirconium alloys are used as cladding materials in nuclear reactors due to their low absorption cross section for thermal neutrons, high corrosion resistance and good mechanical properties. Despite their suitability for use in the nuclear reactor environment, zirconium alloys can develop dimensional instabilities during service as a consequence of irradiation creep, thermal creep and irradiation growth. Irradiation growth is a change in the shape of the zirconium component, in the absence of an applied stress, due to fast neutron fluence. Dimensional instabilities have been found to be dependent on neutron dose, 
temperature, alloy chemistry, texture and degree of cold work, but the phenomenon is still not fully understood.

Nb-containing Zr-alloys were originally developed in the 1950 and the more recent development of the ZIRLO ${ }^{\mathrm{TM}}$ family is based on empirical findings from the performance of earlier alloy systems to improve corrosion behaviour and the resistance to irradiation growth [1, 2]. Whilst this empirical approach proved successful, a full understanding of the mechanisms governing irradiation growth is still missing. It has been established that the redistribution of alloying elements under the influence of irradiation plays a central role in irradiation growth [3]. Regarding the redistribution of alloying elements, the effect of irradiation on the second phase particles (SPPs) in the alloy is especially important. Zircaloys contain the alloying elements $\mathrm{Sn}, \mathrm{Fe}, \mathrm{Cr}$ and, in the case of Zircaloy-2, also Ni. In these materials Fe has been observed to dissolve from FeCr-type as well as from Fe-Ni-type SPPs [4, 5]. Often the Fe-Cr-type SPPs amorphise while the Fe dissolves [6]. Cr is also lost from the particles, which finally leads to the dissolution of the SPP. These elemental redistribution processes are expected to increase the interstitial solute concentration in the matrix, which has been linked previously to the formation of <c>-loops [7-10], i.e. $<$ c $>$-component dislocation loops with a Burgers vector of $<20 \overline{2} 3>$. This formation of $<\mathrm{c}>$-loops has been correlated with an acceleration in irradiation growth $[5,7]$.

In the ZIRLO ${ }^{\mathrm{TM}}$ alloys, which contain the alloying elements $\mathrm{Nb}, \mathrm{Sn}$ and $\mathrm{Fe}$, two types of second phase particle are usually observed [2]; One is Nb-rich with a bcc crystal structure ( $\beta$-Nb-SPP), and the other SPP is a Laves-phase with hcp crystal structure containing $\mathrm{Zr}, \mathrm{Nb}$ and $\mathrm{Fe}$. The stability of these particles under irradiation has not previously been studied for Low Tin ZIRLOTM. Low Tin ZIRLO $^{\mathrm{TM}}$ is an alloy of the ZIRLO ${ }^{\mathrm{TM}}$ family with reduced tin content that has been developed recently to further enhance the corrosion properties [11].

The present work pursues two principle objectives. Firstly, we aim to study the effect of irradiation on the chemical composition of the second phase particles in Low Tin ZIRLO ${ }^{\mathrm{TM}}$ in order to establish the elemental redistribution processes 
and the stability of the SPPs in this alloy system. The detailed elemental characterisation aims to elucidate the mechanisms responsible for the improved resistance to irradiation growth of $\mathrm{Zr}-\mathrm{Nb}-\mathrm{Sn}-\mathrm{Fe}$ alloys compared to conventional non- $\mathrm{Nb}$ containing $\mathrm{Zr}$ alloy systems. In addition, neutron as well as protonirradiated Low Tin ZIRLO ${ }^{\mathrm{TM}}$ was studied in order to investigate if similar damage processes occur in the material independent of the species used for irradiation. The advantage of studying proton rather than neutron-irradiated material is that high doses can be achieved in relatively short times and at moderate cost compared to neutron irradiation. Another important feature of proton-irradiated material is that any activation is usually very short lived (in the order of weeks when irradiated at $2 \mathrm{MeV}$ ). Consequently, any subsequent examination is carried out on samples that are not radioactive, which makes handling and analysis of the material significantly more straight-forward. The use of protons as a surrogate for neutron irradiation has been used extensively for studying effects such as irradiation-induced segregation (IIS) in nuclear plant materials (i.e. stainless steel) $[12,13]$. Examples of using protons to simulate irradiation effects in $\mathrm{Zr}$ cladding materials are less frequent despite promising results having generated typical defect structures, irradiation-induced precipitation and irradiation-induced growth in $\mathrm{Zr}$ alloys [14-17]. However, the significantly higher dose rates of proton compared to neutron irradiation mean that the kinetics of irradiation-induced segregation might be considerably different compared to in-reactor neutron-irradiated material. Since fast diffusing elements such as Fe have often been linked to $<\mathrm{c}>$ loop formation [8-10], it is clear that detailed IIS studies are an essential benchmarking exercise to identify if defect structures might nucleate under similar circumstances as compared to neutron irradiation.

\section{Experimental methods}

The material studied here is the commercial zirconium alloy Low Tin ZIRLOTM (1wt\% Nb, 0.7wt\% Sn, 0.1wt\% Fe; Westinghouse Electric Company), which was 
supplied in tube form in the fully recrystallised condition. Further information on the processing route can be found in reference [18].

The neutron-irradiated Low Tin ZIRLO ${ }^{\mathrm{TM}}$ material was supplied by Studsvik and Westinghouse in the form of electropolished $3 \mathrm{~mm}$ disc prepared as foils for transmission electron microscope (TEM) imaging. These samples were taken from fuel channel material that was irradiated for 5 cycles at the Oskarshamm 3 nuclear power plant and reached a burnup of $49 \mathrm{MWd} / \mathrm{kgU}$. The samples tested here were exposed to a fast neutron fluence of 8.9-9.0 $\times 10^{25} \mathrm{n} / \mathrm{m}^{2}$. It is difficult to find agreement in the literature with regards to a conversion of neutron fluence to dpa. Indeed, Fidleris, Tucker and Adamson (1987) note that conversion factors can range from $1 \mathrm{dpa}=5 \times 10^{24} \mathrm{n} \mathrm{m}^{-2}$ to $1 \times 10^{25} \mathrm{n} \mathrm{m}^{-2}$, depending on the displacement energy used in the calculation [19]. In agreement with the lower end of this range, Griffiths, Gilbert and Carpenter used individual reactor spectra to calculate a conversion factor for Zircaloy-2 in a BWR environment as $1 \mathrm{dpa}=5 \times 10^{24} \mathrm{n} \mathrm{m}^{-2}$ [20], which was further confirmed elsewhere [21]. This value has been used to convert the fluence of the samples in the present study from $8.9-9.0 \times 10^{25} \mathrm{n} \mathrm{m}^{-2}$ to $\sim 18 \mathrm{dpa}$. This value is thought to be at the lower end of what might be considered to be the breakaway growth regime in ZIRLOTM [22].

The proton-irradiation experiments were performed at the Michigan Ion Beam Laboratory's $1.7 \mathrm{MeV}$ Tandertron acceleration facility. The 2 × 2 × $20 \mathrm{~mm}$ bars were irradiated at $350 \pm 9^{\circ} \mathrm{C}$ with $2 \mathrm{MeV}$ protons at a high frequency raster with a current of $\sim 0.2 \mu \mathrm{A} \mathrm{mm}^{-2}$ on the stage, an area defined by a $10 \times 18 \mathrm{~mm}$ tantalum aperture. The temperature was chosen in accordance with previous work that suggests comparable <c>-loop sizes between neutron irradiation and proton irradiation at $350^{\circ} \mathrm{C}$ [16]. The SRIM (The Stopping and Range of Ions in Matter) software was used to simulate the damage profile of the protons in pure $\mathrm{Zr}$ (Figure 1) using a displacement energy for $\mathrm{Zr}$ of $40 \mathrm{eV}$ [23] and the "Quick" Kinchin and Pease damage calculation, as recommended by Stoller et al. [24]. Figure 1 shows the Bragg peak (pronounced peak on the Bragg curve where the protons loose most of their energy when they travel through $\mathrm{Zr}$ ) at around 28 $\mu \mathrm{m}$, which is the position where the hydrogen accumulates. The electropolished 
foil was prepared in the relatively uniform damage region, $<60 \%$ of the Bragg peak, at a position corresponding to $\sim 12 \mu \mathrm{m}$ penetration depth for $7 \mathrm{dpa}$ and is shown in Figure 1. The damage, D, in displacements per atom (dpa), and hence the damage rate at $12 \mu \mathrm{m}$ depth was calculated to be $\sim 7.5 \times 10^{-6} \mathrm{dpa} \mathrm{hr}^{-1}$ using the following equation [25]:

$$
D=\frac{\Phi \bullet N_{d} \bullet M_{r}}{\rho \bullet d \bullet N_{A}}
$$

where $\Phi$ is the proton fluence, $N_{d}$ is the number of displacements per ion, given by SRIM, $M_{r}$ is the molecular mass of the target material, $\rho$ is it's density, $d$ is the penetration depth of the ion and $\mathrm{N}_{\mathrm{A}}$ is Avogadro's number. The Low Tin ZIRLO ${ }^{\mathrm{TM}}$ material was irradiated to 2.3 and $7 \mathrm{dpa}$ according to these calculations.

The irradiated bars ( $2 \mathrm{~mm}$ thick) were prepared for TEM by grinding carefully to $\sim 160 \mu \mathrm{m}$ from the non-irradiated surface, punching with a mechanical $3 \mathrm{~mm}$ hole punch and then final electropolishing using a twin-jet Tenupol-5 electropolisher with a Julabo FP50 cooling unit. An electrolyte of 10\% perchloric acid and 20\% 2-Butoxyethanol in ethanol [16] was used, as it has been found to minimise the introduction of artifacts due to sample preparation. A temperature of $0 \pm 0.5^{\circ} \mathrm{C}$ and a voltage of $22 \mathrm{~V}$ at a medium flow rate were found to be optimal for the Low Tin ZIRLOTM alloy. The $3 \mathrm{~mm}$ disk was polished initially from both faces to a depth approximating 60\% away from the Bragg peak on the irradiated side. The dissolution rate was followed with a uscan $₫$ nanofocus laser profiler. Subsequently, the irradiated face was protected from the electrolyte with Agar Scientific's Lacomit varnish and the non-irradiated side was further polished until perforation. Finally, the Lacomit was removed by dissolution in acetone and final cleaning in a Fischione plasma cleaner was found to be necessary for the removal of residual hydrocarbons.

To prepare the non-irradiated tube material for investigation in the TEM, samples were sectioned and ground down carefully to a thickness of $150 \mu \mathrm{m}$, before $3 \mathrm{~mm}$ discs were punched out. The discs were electropolished using a Struers Tenupol Twin-Jet Electropolisher with a solution of $10 \%$ perchloric acid in methanol at $-40^{\circ} \mathrm{C}$ and $20 \mathrm{~V}$. The neutron-irradiated material followed the 
same sample preparation procedure but was carried out by STUDSVIK NUCLEAR (Sweden) in their hot cell laboratory.

TEM imaging and analysis was performed using an aberration-corrected fieldemission gun scanning transmission electron microscope (STEM) capable of high resolution EDX spectrum imaging (FEI Titan G2 80-200kV S/TEM "ChemiSTEMTM"). Four EDX detectors with a total collection angle of $0.7 \mathrm{srad}$ allow fast data acquisition independent of the tilt angle of the sample [26]. High angle annular dark field (HAADF) STEM imaging was performed at an accelerating voltage of $200 \mathrm{kV}$ with a probe current of $0.2 \mathrm{nA}$. The probe convergence semi-angle was $18 \mathrm{mrad}$ and the HAADF inner angle was $54 \mathrm{mrad}$. Local compositional analysis was obtained from the EDX spectra using the CliffLorimer quantification approach implemented within the Bruker ESPRIT software. However, due to the absence of reliable standards, as well as uncertainties regarding the precise X-ray take-off angles and sample thickness, the results are best described as semi-quantitative. Quantification of the composition of the nanometer scale second phase particles is further complicated by the unknown contribution from the surrounding matrix to the signal. Depending on the particle size and the position of the particle in the electropolished foil, the contribution of the matrix to the signal can vary significantly. This will result in significant uncertainty regarding the concentration of zirconium in the particles, as the matrix is mainly composed of this single element. For the neutron-irradiated material, the acquisition of a 'dark' background spectrum (with the electron beam blanked) was also required as the radioactive material emits characteristic $\mathrm{K} \alpha \mathrm{Nb}$ and $\mathrm{Zr} \mathrm{X}$-rays. This background had to be subtracted from the acquired EDX spectra before quantification. The presence of $\mathrm{Nb} \mathrm{K \alpha}$ peaks in the background spectrum means that especially the quantification of the $\mathrm{Nb}$ concentration is further complicated. Despite these limitations, the high spatial resolution compositional results shown here still provide important insights into the compositional evolution under irradiation, even if the absolute values should not be overanalysed.

A structural analysis of SPPs was performed in a FEI Tecnai F30 FEG-TEM at the University of Manchester by use of the ASTAR automated crystal orientation 
mapping system [27], coupled with precession [28] at $0.8^{\circ}$ and a rate of $100 \mathrm{~Hz}$ using the NanoMegas precession system to reduce dynamical effects. Precession typically increases the number of spots and improves the reliability of solutions [29] when indexed by comparison to simulated kinematical diffraction patterns in the ASTAR Index software V1.4. A probe diameter of $\sim 3 \mathrm{~nm}$ was formed in TEM mode by using a $20 \mu \mathrm{m}$ diameter condenser C2 aperture and a small spot size, resulting in a low beam current of $\sim 26 \mathrm{pA}$. The rotation between the diffraction plane and the image plane was calibrated using a crystal of known orientation. The beam was scanned across the area of interest and the resulting Precession NanoBeam Electron Diffraction (Y-NBED; "Y" being used as notation for precession due to the conical shape of the letter itself) patterns were recorded as a function of position and indexed according to phase and orientation. This procedure on the same microscope has been used successfully by Garner et al. to study the microstructure and microtexture of oxide films growing on Zr alloy Zircaloy-4 [30].

\section{Results}

Figure 1 shows the profile of damage in units of dpa with respect to the penetration depth of $2 \mathrm{MeV}$ protons in pure $\mathrm{Zr}$. This output of SRIM in displacements ion- $1 \AA-1$ is converted to dpa per unit time using equation (1) for $\mathrm{D}$, damage, and then each data point is multiplied by the time for the $7 \mathrm{dpa}$ irradiation experiment. It should be noted that SRIM does not take into account recombination or thermal effects. Although the accuracy of such a calculation may be called into question, use of the Kinchin-Pease model allows comparison to the reference Norgett, Robinson and Torrens standard for calculating damage in neutron-irradiated material [24].

Figure 2 shows HAADF STEM images of the second phase particles found in Low Tin ZIRLO ${ }^{\mathrm{TM}}$ prior to irradiation. Although EDX spectrum images were acquired in order to determine what type of SPPs are present in the material, the atomic number contrast from the HAADF give an indication of the particle chemistry; $\beta$ - 
$\mathrm{Nb}$ particles have a higher average atomic weight than $\mathrm{Zr}-\mathrm{Nb}-\mathrm{Fe}$ particles and so appear brighter in the image.

Figure 3 presents the results of an EDX microanalysis of a second phase particle in Low Tin ZIRLO ${ }^{\mathrm{TM}}$. The elemental distributions for $\mathrm{Fe}, \mathrm{Nb}$ and $\mathrm{Zr}$, obtained from the EDX spectrum image maps in (Figure 3c-f) show that the particle is rich only in niobium and depleted in zirconium relative to the matrix, which suggests that it is a $\beta-\mathrm{Nb}$ particle. Interestingly, segregation of iron to the particle interface is evident in the spectrum image (Figure $3 \mathrm{~d}$ ) as well as in the results from a separately acquired EDX spectra line scan across the particle interface (Figure 3b). The compositional data extracted from the line scan shows a peak concentration of more than $6 \mathrm{wt} . \%$ in the boundary area compared to less than 1wt.\% in the particle and matrix. This enrichment of the particle's boundary with iron has not been reported previously.

After neutron irradiation to $18 \mathrm{dpa}$, the $\beta-\mathrm{Nb}$ SPPs are still present in the material. However, the Fe enrichment at the SPP interface is found to be either greatly reduced (to a level of less than 1wt.\% for the particle shown in Figure 4) or more commonly entirely absent (Figure 5). In the former case, the distribution of Fe on the interface boundary appears to be more clustered than before irradiation although this may result simply from the lower signal-to-noise ratio. Similar redistribution of Fe away from the SPP interface was also observed in the material that was proton-irradiated (Figure 6). Even after proton irradiation to only $2.3 \mathrm{dpa}$ the Fe enrichment around the $\beta$-Nb-SPPs is no longer observed, as shown in the EDX spectrum elemental maps in Figure 6. It is interesting to note that in contrast to the neutron-irradiated sample, no $\beta-\mathrm{Nb}$ particles with slight $\mathrm{Fe}$ decoration of the interface were found after proton irradiation, even though the level of damage is much lower. Despite this lack of an intermediate stage, these observations demonstrate that similar processes of Irradiation-induced elemental redistribution take place during proton and neutron irradiation. Precession NanoBeam electron Diffraction (Y-NBED) patterns from $\beta$-Nb SPPs after neutron irradiation to $18 \mathrm{dpa}$ and protonirradiation to 2.3 and 7 dpa indicate that the SPP has retained its crystallinity 
and has been successfully indexed as the bcc $\beta$-Nb phase; no amorphisation of any particles has been observed.

As the solubility of iron in zirconium is extremely low [31], iron-containing second phase particles are formed in Low Tin ZIRLO ${ }^{\mathrm{TM}}$ in addition to the $\beta-\mathrm{Nb}$ SPPs [2]. The presence of Zr-Nb-Fe SPPs was confirmed in the EDX microanalysis (Figure 7). Small amounts of $\mathrm{Cr}$ were found homogeneously distributed throughout the SPPs in the order of 1.5 to $2 \mathrm{wt}$.\%, even though $\mathrm{Cr}$ is only present as an impurity element (less than $100 \mathrm{ppm}$ ) in the alloy, and so these types of SPPs will be refered to as $\mathrm{Zr}-\mathrm{Nb}-\mathrm{Fe}(-\mathrm{Cr})$ for the remainder of this report. This has been reported previously for ZIRLO ${ }^{\mathrm{TM}}$ by Sabol et al. [32]. All elements are evenly distributed in the particles and no enrichment or depletion is seen on the interface boundaries prior to irradiation.

Remarkable changes in the composition of the $\mathrm{Zr}-\mathrm{Nb}-\mathrm{Fe}(-\mathrm{Cr})$ SPPs were observed in the neutron-irradiated material. After 18dpa Fe is no longer found in the SPP and $\mathrm{Cr}$ is only seen in the core of the particle (Figure 8). The Cr also seems to be accumulated in small clusters in the core of the particle rather than evenly distributed as before irradiation. Y-NBED patterns were acquired using the NanoMegas and ASTAR systems either side of the Cr core in Figure 8 (Figure 9). These diffraction patterns have been successfully indexed as arising from the bcc $\beta-\mathrm{Nb}$ phase and so the hcp to bcc phase transformation is confirmed, as it has been by Shishov et al. [33]. The orientation of the transformed $\mathrm{Zr}-\mathrm{Nb}-\mathrm{Fe}(-\mathrm{Cr})$ SPP either side of the $\mathrm{Cr}$ core is different with a misorientation of $\sim 33^{\circ}$, suggesting that the $\mathrm{Cr}$ core acts as a nucleation site for multiple orientations within the particle. This is an observation that has not been reported previously. Please note that the left hand side of the particle has two possible orientations; the $<\overline{656}>$ and the $<656>$. As these orientations are close to the high symmetry $<111>$ zone axis, the diffraction patterns are too similar to distinguish. The right hand size of the particle, however, is in a low symmetry orientation and so can be indexed accurately as the $<\overline{216}>$.

A loss of Fe from the $\mathrm{Zr}-\mathrm{Nb}-\mathrm{Fe}(-\mathrm{Cr}) \mathrm{SPPs}$ is also observed in the protonirradiated material. Semi-quantitative compositions of the $\mathrm{Zr}-\mathrm{Nb}-\mathrm{Fe}(-\mathrm{Cr}) \mathrm{SPPs}$ 
were calculated from EDX spectrum images and are presented in Figure 10 for the non-irradiated as well as the irradiated material. Whilst the $\mathrm{Fe}$ and $\mathrm{Nb}$ content in this type of SPP is almost identical before irradiation, the amount of Fe in the particle is already noticeably reduced in the material proton-irradiated to only $2.3 \mathrm{dpa}$. The trend continues in the material that was proton-irradiated to $7 \mathrm{dpa}$ where an even lower Fe content is found in the SPPs and Fe reaches undetectable levels when neutron-irradiated to 18dpa. Unfortunately, despite the relatively high dose rate of proton irradiation compared to neutron irradiation, only comparatively small doses of 2.3 and $7 \mathrm{dpa}$ were achieved in the given time at the proton irradiation facility. Hence, no direct comparison of equivalent irradiation conditions for both protons and neutrons is currently available. Even so, the trend observed in Figure 10, despite combining different irradiation sources, is remarkable.

The EDX spectrum images of an SPP that was irradiated to 7dpa using protons (Figure 11) show that the loss of Fe from the particle is not a uniform process, but starts from the edges of the particle. After $7 \mathrm{dpa}, \mathrm{Fe}$ is only found in the centre of the particle. Anisotropic dissolution of alloying elements, along the [10 $\overline{1} 0]$ direction and within the basal planes, has been observed previously for Fe-Crtype precipitates $[4,34,35]$, although there is no evidence of that process in the current work. Similar to the neutron-irradiated material, the distribution of $\mathrm{Cr}$ also changes during proton irradiation to $7 \mathrm{dpa}$ and exhibits noticeable clustering. However, $\mathrm{Cr}$ remains in a larger region than $\mathrm{Fe}$.

To aid comparison of the $\mathrm{Fe}$ and $\mathrm{Nb}$ contents within the $\mathrm{Zr}-\mathrm{Nb}$-Fe-SPPs, line scans were extracted from the EDX spectrum images across the particle-matrix interface for both the non-irradiated and the irradiated materials (Figure 12). In the non-irradiated material these two elements show a 1:1 ratio. However, in the $2.3 \mathrm{dpa}$ and $7 \mathrm{dpa}$ proton-irradiated material the $\mathrm{Fe}$ content increases considerably more slowly from the matrix to the centre of the particle than that of the $\mathrm{Nb}$, demonstrating $\mathrm{Fe}$ dissolution from the edge of the particle but not from the core. A greater difference in gradient is seen in the Fe concentration from the centre to the edge of the particle for the lower level of damage (Figure $12 \mathrm{~b}$ ) in agreement with the established evolution of the Fe redistribution during 
proton irradiation. After 2.3dpa the Fe level in the centre of the particle is still comparable to that before irradiation. The main change in the Fe concentration is found on the edges of the SPP, where the Fe concentration is much lower than before irradiation. No such evolution can be deduced regarding the $\mathrm{Nb}$ concentration. Comparing the slopes of the $\mathrm{Nb}$ concentration on the edge of the particle before and after irradiation does not show any conclusive changes. Of course this slope will also be affected by the way the particle is cut when the TEM foil is prepared, which makes a comparison more difficult. An additional complicating factor is that for the neutron-irradiated material the $\mathrm{Nb} \mathrm{K \alpha}$ background could not be subtracted at each point. Instead, the $\mathrm{Nb}$ concentration was adjusted by subtracting the background level in the matrix area and then multiplying the $\mathrm{Nb}$ composition with a factor in order to match the previously quantified concentration in the particle. Despite these uncertainties, the slopes of the $\mathrm{Nb}$ concentration on the edge of the particles appear qualitatively similar for all four conditions. This suggests that there is indeed no loss of $\mathrm{Nb}$ from the particle edges during proton or neutron irradiation.

Y-NBDPs were obtained from different regions of the proton-irradiated SPP in Figure 11 (Figure 13). Diffraction patters 1, 2 and 3 are from the centre, the Fedepleted zone and the $\alpha$-Zr matrix, respectively. Pattern 2 shows extra reflections, circled in red, that are not present in the Fe-rich region or in the matrix, suggesting that a phase transformation may be occurring in the Fedepleted region. There is some diffuse scattering in patterns 1 and 2 close to the direct beam; it is the author's opinion that this scattering is due to a highly defective structure and possibly the presence of Cr clusters within the SPP. It cannot be said with any confidence that this is due to any amorphisation, as the particle clearly has retained some degree of crystallinity. However, due to the diffuse scattering and the highly defective intermetallic structure, it was not possible to index these patterns.

It is worth noting here that the work to date has not focused on identifying possible irradiation-induced precipitation of SPPs, as it most likely requires the combination of the present technique with 3D atom probe analysis. Work has started on this and will be reported in the future. 


\section{Discussion}

The results presented here show that during the irradiation of Low Tin ZIRLOTM redistribution of the alloying elements occurs. Most significant is the redistribution of $\mathrm{Fe}$ in the alloy. Iron is lost from the Zr-Nb-Fe-SPPs as well as from the interface of the $\beta$-Nb-SPPs during neutron and proton irradiation. Loss of iron from second phase particles has been observed in a range of zirconium alloys as a consequence of irradiation [10, 36-38]. This redistribution means that the iron concentration in the matrix is very likely to increase during irradiation, which is expected to affect corrosion performance [39, 40], plasticity [41, 42] and dimensional instability [41]. It should be noted at this stage that work is currently underway to analyse grain boundaries, which are also decorated with Fe before irradiation, and there are preliminary indications that $\mathrm{Fe}$ is again injected into the matrix during irradiation although a complete analysis of this is beyond the scope of this report.

Unfortunately, for the present study neutron-irradiated samples were only available for the high 18dpa level making a direct comparison of the redistribution of elements for the two types of irradiative species difficult. Despite the significant difference in the dose levels, very good qualitative agreement was found between the compositional changes in the proton- and neutron-irradiated material, indicating that similar processes regarding elemental redistribution occur during neutron and proton irradiation. It is interesting that even at the low damage levels achieved by proton irradiation such clear evidence of elemental redistribution processes was observed. Unfortunately, it is impossible to tell at this point whether these processes are simply initiated at an earlier point in the irradiation history for proton irradiation (due to the high dose rate) or whether the loss of Fe would also be observed this early for neutron irradiation. In contrast to the observations reported here, no changes in the composition of the second phase particles were found in a recent study of ZIRLOTM using heavy $\mathrm{Ni}^{+}$ions (400 keV) at room temperature and electron irradiation $(1250 \mathrm{keV})$ at $300^{\circ} \mathrm{C}$, highlighting the importance of the irradiative species and the temperature used for irradiation [43]. In the same study, the $\mathrm{Zr}-\mathrm{Nb}-\mathrm{Fe}(-\mathrm{Cr}) \mathrm{SPPs}$ were shown to become 
amorphous during the $\mathrm{Ni}^{+}$ion irradiation by a dose of $5 \mathrm{dpa}$. In the present case, the use of protons for irradiation at $350^{\circ} \mathrm{C}$ appears to mimic the effects of neutron irradiation better than the use of $\mathrm{Ni}^{+}$ions or electrons in terms of both the SPP chemical evolution and the changes in SPP structure. The hcp to bcc phase transformation of the $\mathrm{Zr}-\mathrm{Nb}-\mathrm{Fe}(-\mathrm{Cr})$ SPPs has ben shown here for the neutron case and there is an indication of a phase change for the proton case; higher dose levels are required for further Fe dissolution to initiate such a change in structure. Tournadre et al. compared the effect of proton and zirconium ion irradiation on Zircaloy-4 with neutron irradiation [16]. It was found that the damage structures generated by proton irradiation compare better to the ones generated by neutrons. This was attributed to the fact that the damage rate of protons is closer to the one of neutrons than when heavier ions are used, although it should be pointed out that the dose rate of proton irradiation is still usually about 100 times higher than for neutron irradiation [17]. Previous studies on other zirconium alloys have also established that proton irradiation produces damage characteristics comparable to that of neutron irradiation in the material [15-17].

Whilst changes in the Fe distribution are well established for the Zircaloys, the alloy family of ZIRLO ${ }^{\mathrm{TM}}$ is a more recent development and hence not as well studied regarding compositional and microstructural changes due to irradiation. Depletion of Fe from Zr-Nb-Fe-type second phase particles has however been reported after neutron irradiation of the alloy E635, which has a similar composition to ZIRLOTM $[2,36,37]$. The concentration of Fe in the matrix was also shown to increase accordingly. Dispersion of iron from a Zr-Nb-Fe-Cr-type precipitate was also found in a $\mathrm{Zr}-2.5 \mathrm{Nb}$ pressure tube material during irradiation at $300^{\circ} \mathrm{C}$ [38]. These results agree very well with the findings of the present study.

The decoration of $\beta$ - $\mathrm{Nb}$ particles by Fe before irradiation is not surprising as $\mathrm{Fe}$ has a low solubility in $\beta-\mathrm{Nb}$ and $\alpha-\mathrm{Zr}$ and therefore tends to segregate to interfaces. It might be the case that the creation of dislocation loops during irradiation creates more attractive sites for Fe, which could explain the dramatic 
decrease of Fe decoration. However, more detailed studies, including grain boundary analysis, are necessary to draw firm conclusions.

In the Zircaloys, the depletion of $\mathrm{Fe}$ (and $\mathrm{Cr}$ ) from second phase particles during irradiation has been linked to the formation of $<$ c>-loops [8-10], which is believed to cause irradiation growth in zirconium alloys. The Nb-containing alloys, such as ZIRLO ${ }^{\mathrm{TM}}$, show a much higher resistance to irradiation growth than the Zircaloys [32, 37, 44], even though they seem to undergo similar redistribution processes of the interstitial alloying elements during irradiation as shown here. In both alloy systems, Fe depletes preferentially from the second phase particles, while $\mathrm{Cr}$, as the slower diffusing species, takes longer to leave the particles and is still found in the core even after neutron irradiation up to high fluencies, as observed here. It has even been suggested that the depletion of Fe might occur more rapidly for the type of second phase particle found in ZIRLO $^{\text {TM }}$ than it does in Zircaloy-2 [38]. One might think that the growth performance of ZIRLO ${ }^{\mathrm{TM}}$ under irradiation should be worse than that of Zircaloy2. However, the opposite is observed. Shishov et al. also showed that an increase in the Fe content lead to reduced $<$ c $>$-loop formation and less irradiation growth in the alloy E635 with a similar composition to ZIRLO ${ }^{\mathrm{TM}}$ [37]. It has been speculated that in alloys like Low Tin ZIRLO ${ }^{\mathrm{TM}}$ the Fe content in the matrix phase affects the distribution of the substitutional alloying elements such as $\mathrm{Nb}$ [8]. Most interestingly, substitutional alloying elements have been seen to suppress $<\mathrm{c}>$-loop formation in zirconium alloys but no mechanism was discussed to explain this phenomenon [45]. In Zr-Nb-Sn-Fe type alloys, there are several possibilities for substitutional elements supressing <c>-loop formation. Firstly, while in Zircaloy type alloys the only substitutional element with any noticeable solubility is $\mathrm{Sn}$, in $\mathrm{Zr}-\mathrm{Nb}-\mathrm{Sn}-\mathrm{Fe}$ type alloys there are $\mathrm{Nb}$ and $\mathrm{Sn}$. Both elements do reduce the lattice spacing of $\mathrm{Zr}$ but this effect is 5 times greater for $\mathrm{Nb}$ than $\mathrm{Sn}$ $[46,47]$. Important to note at this stage is that Fe displays ultra-fast diffusion rates in $\mathrm{Zr}$ that have been explained by a mechanism of interstitial Fe/vacancy pairing [48]. If one assumes that lattice parameter reduction does decrease the likelihood of $\mathrm{Fe}$ being interstitial, it seems possible that the presence of $\mathrm{Nb}$ (in combination with $\mathrm{Sn}$ ) reduces the effectiveness of Fe being a nucleation site for 
vacancy loops, i.e. <c>-loops. In addition, Zr-Nb-Sn-Fe type alloys have further potential sources of $\mathrm{Nb}$ in the form of $\beta-\mathrm{Nb}$ and $\mathrm{Zr}-\mathrm{Nb}-\mathrm{Fe}-\mathrm{SPPs}$ that could increase the $\mathrm{Nb}$ content of the matrix if $\mathrm{Nb}$ was to leave those SPPs as Fe does. Although the present work has not yet been able to provide clear evidence for $\mathrm{Nb}$ diffusing out of the two types of SPPs, Shishov et al. showed by particle extraction and subsequent EDX microanalysis that $\mathrm{Nb}$ content in $\beta$ - $\mathrm{Nb}$ particles depletes from $85-90 \%$ to $\sim 50 \%$ after neutron irradiation to doses of 10-23 dpa at $315-350^{\circ} \mathrm{C}$ in a BOR-60 reactor [33]. In fact, the $\mathrm{Nb}$ content determined in the Zr-Nb-Fe-SPPs after proton irradiation appeared to increase (Figure 10), but this might mainly be related to the decrease in the Fe content. For the neutronirradiated material, the $\mathrm{Nb}$ content of the SPPs varies greatly as does the $\mathrm{Zr}$ content. It appears that the Zr-Nb-Fe-SPP takes up Zr during irradiation as the Fe leaves the particle. However, it is difficult to separate this effect from the matrix contribution, which will vary depending on sample thickness and the position of the SPP in the sample. Comparing the slopes of the $\mathrm{Nb}$ concentration in the line scans from Zr-Nb_Fe-SPPs (Figure 12) also did not indicate a noticeable loss of $\mathrm{Nb}$ from the edge of the particle. It is clear from the findings to date that significantly more work is needed to determine the potential interplay of $\mathrm{Nb}, \mathrm{Sn}$ and $\mathrm{Fe}$ and their role in <c>-loop formation. However, the extremely high efficiency of advanced STEM EDX detector systems in combination with bright electron sources present a new opportunity to answer those questions.

\section{Summary and Conclusions}

The effect of neutron and proton irradiation on the composition of second phase particles in Low Tin ZIRLO ${ }^{\mathrm{TM}}$ was investigated by EDX spectroscopy. The work benefited from the use of an aberration-corrected field-emission gun scanning transmission electron microscope with four EDX detectors in close proximity to the sample enabling high resolution EDX mapping. The main findings can be summarised as follows: 
- Segregation of Fe to the interface of $\beta$-Nb SPPs was found prior to irradiation. Fe disperses from the interface during neutron as well as proton irradiation.

- Despite being only present in the alloy as an impurity, low levels of homogeneously dispersed $\mathrm{Cr}$ were detected in the intermetallic $\mathrm{Zr}-\mathrm{Nb}$-FeSPPs.

- No Fe was detected in the Zr-Nb-Fe(-Cr) SPPs after neutron irradiation to 18dpa, while Cr remains present clustered in the core of the SPP.

- A phase transformation of the $\mathrm{Zr}-\mathrm{Nb}-\mathrm{Fe}(-\mathrm{Cr}) \mathrm{SPP}$ from the original hcp to bcc $\beta-\mathrm{Nb}$ phase was found for the $18 \mathrm{~d}$ pa neutron case.

- Fe is gradually dispersed from the $\mathrm{Zr}-\mathrm{Nb}-\mathrm{Fe}(-\mathrm{Cr})$ SPPs during proton irradiation, starting from the edges of the particle.

- In the regions of Fe-depletion at the edges of the proton-irradiated $\mathrm{Zr}-\mathrm{Nb}$ $\mathrm{Fe}(-\mathrm{Cr})$ SPPs, extra spots in the diffraction patterns suggest the beginnings of a phase transformation.

- Good qualitative agreement is observed between the elemental redistribution processes introduced by neutron compared to proton irradiation.

Acknowledgements:

The authors would like to thank the EPSRC for financial support under EP/I005420/1 as well as the financial and in-kind support from our industrial partners namely EDF, Rolls-Royce plc, National Nuclear Laboratory and Westinghouse Electric Sweden. A thanks also goes to the experimental officers of our electron microscopy suite, in particularly Mr Matthew Smith, as well as to Prof. Gary Was and his group at the Michigan Ion Beam Laboratory for their support and advice regarding the proton irradiation experiments. The funding for FEI Titan G2 80-200kV S/TEM was 
received from HM Government (UK) and is associated with research capability of the Nuclear Advanced Manufacturing Research Centre. 


\section{Figures}

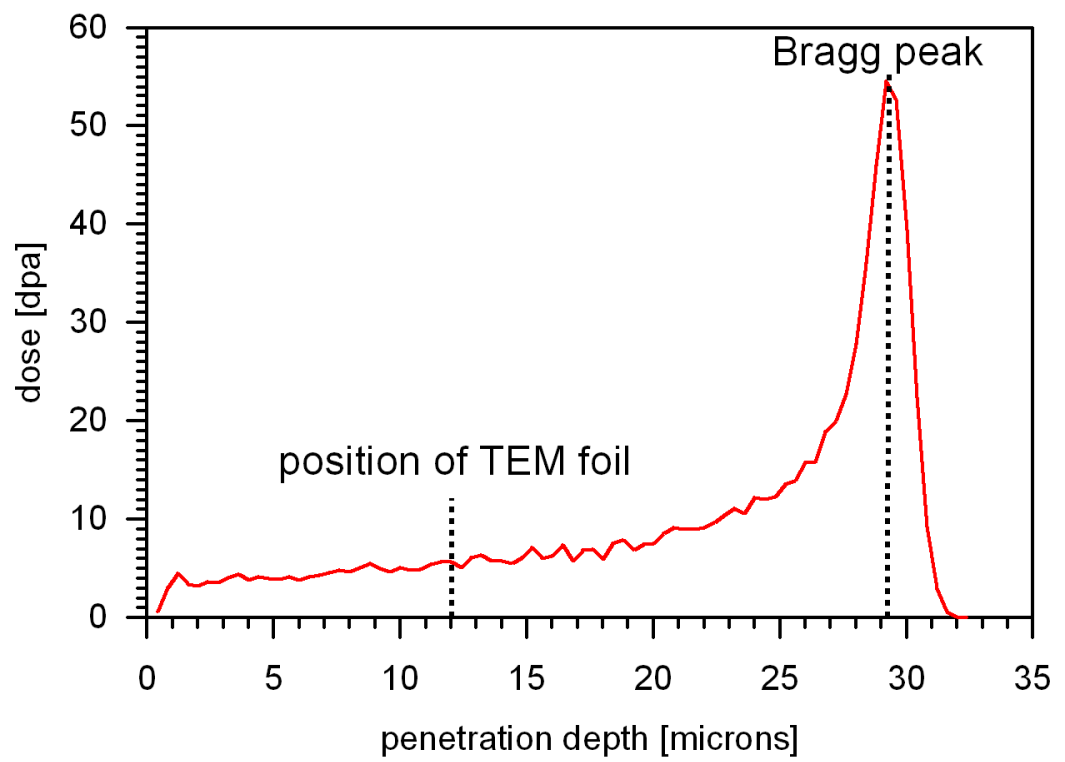

Figure 1: Predicted dpa vs. depth profile using SRIM for 7 dpa assuming pure Zr.

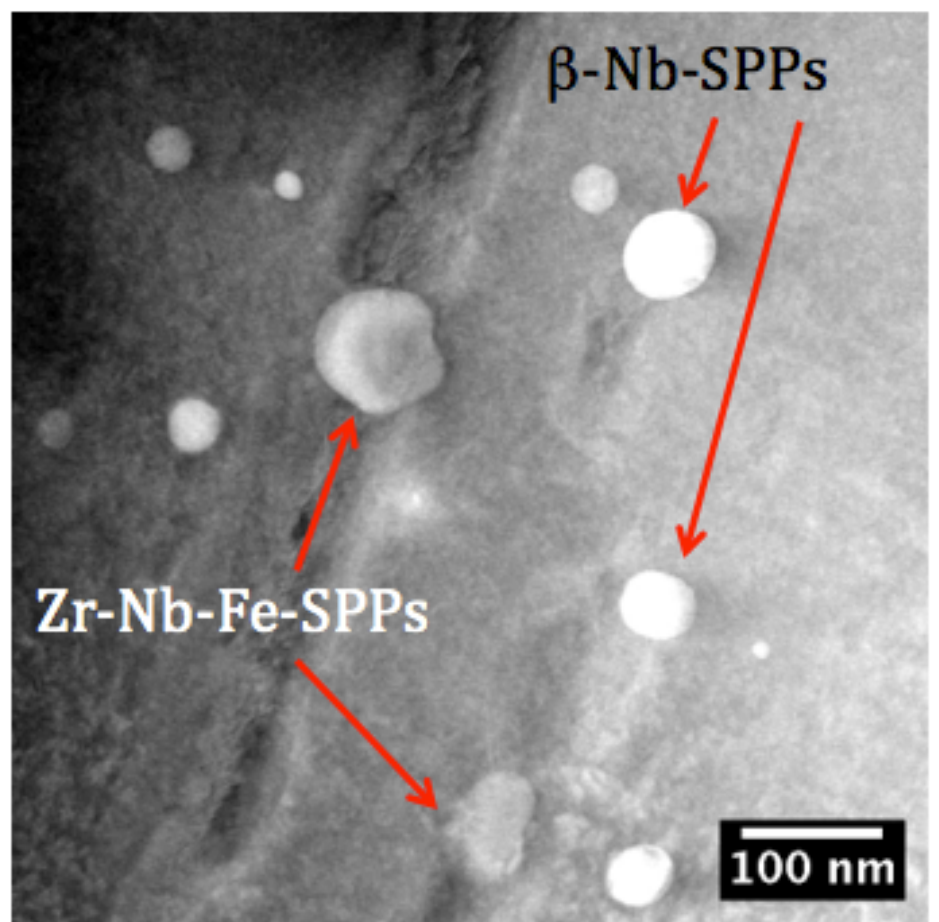

Figure 2: High angle annular dark field STEM image showing second phase particles in Low Tin ZIRLOTM $^{\mathrm{TM}}$ prior to irradiation. 

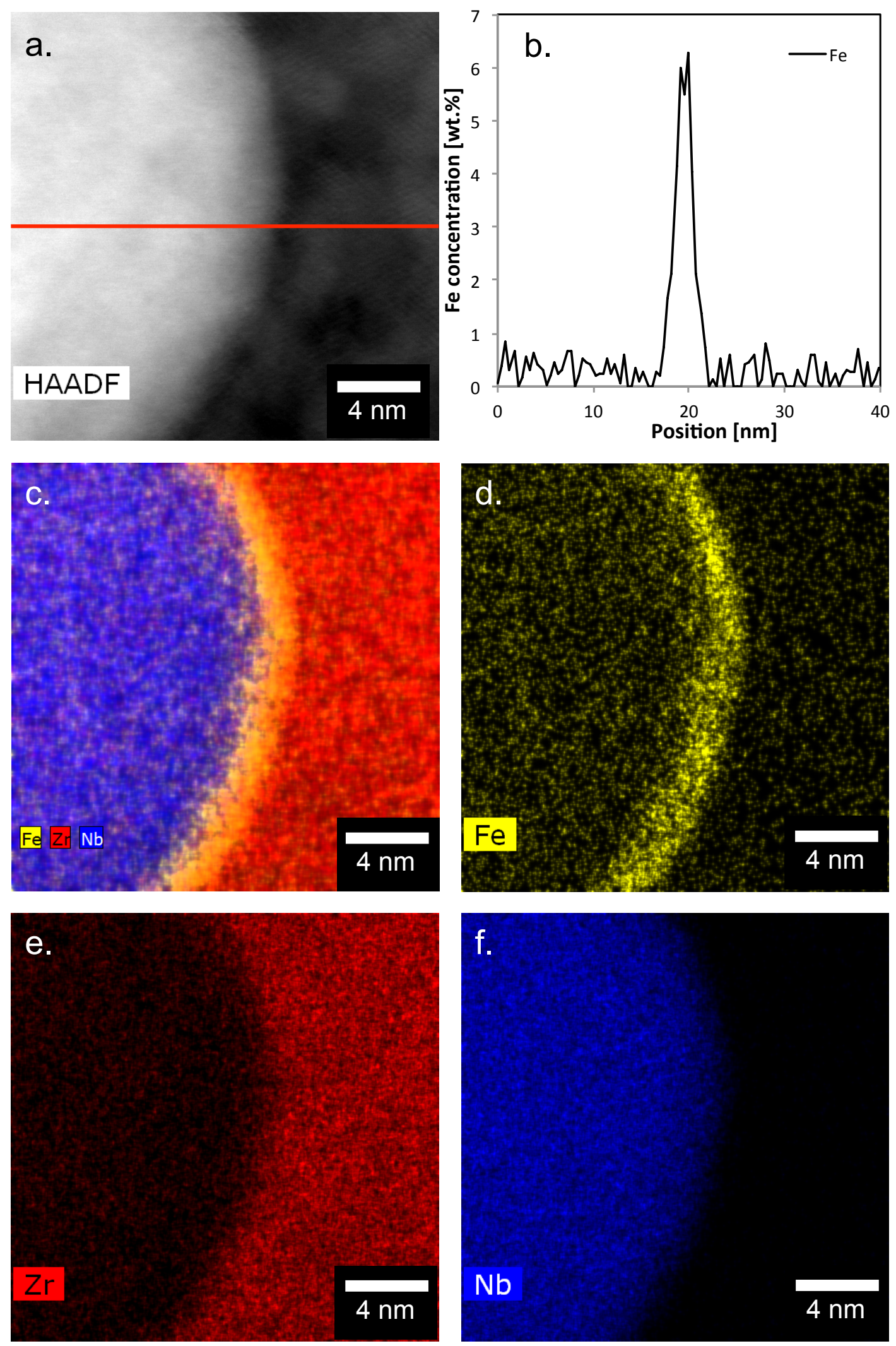

Figure 3: EDX spectrum imaging of a second phase particle (SPP) in Low Tin ZIRLOTM. Iron segregation to the SPP boundary is observed with a concentration of $6.3 \mathrm{wt} \%$ compared to less than $1 \mathrm{wt} \%$ in the surrounding area, a. HAADF image of a second phase particle showing the area for which the EDX spectrum image was acquired; the line indicates where an additional EDX spectrum line scan was acquired, b. quantification of iron concentration from the line scan data showing iron enrichment on the particle boundary, c-f. Elemental maps for the distribution of iron, zirconium and niobium respectively. 

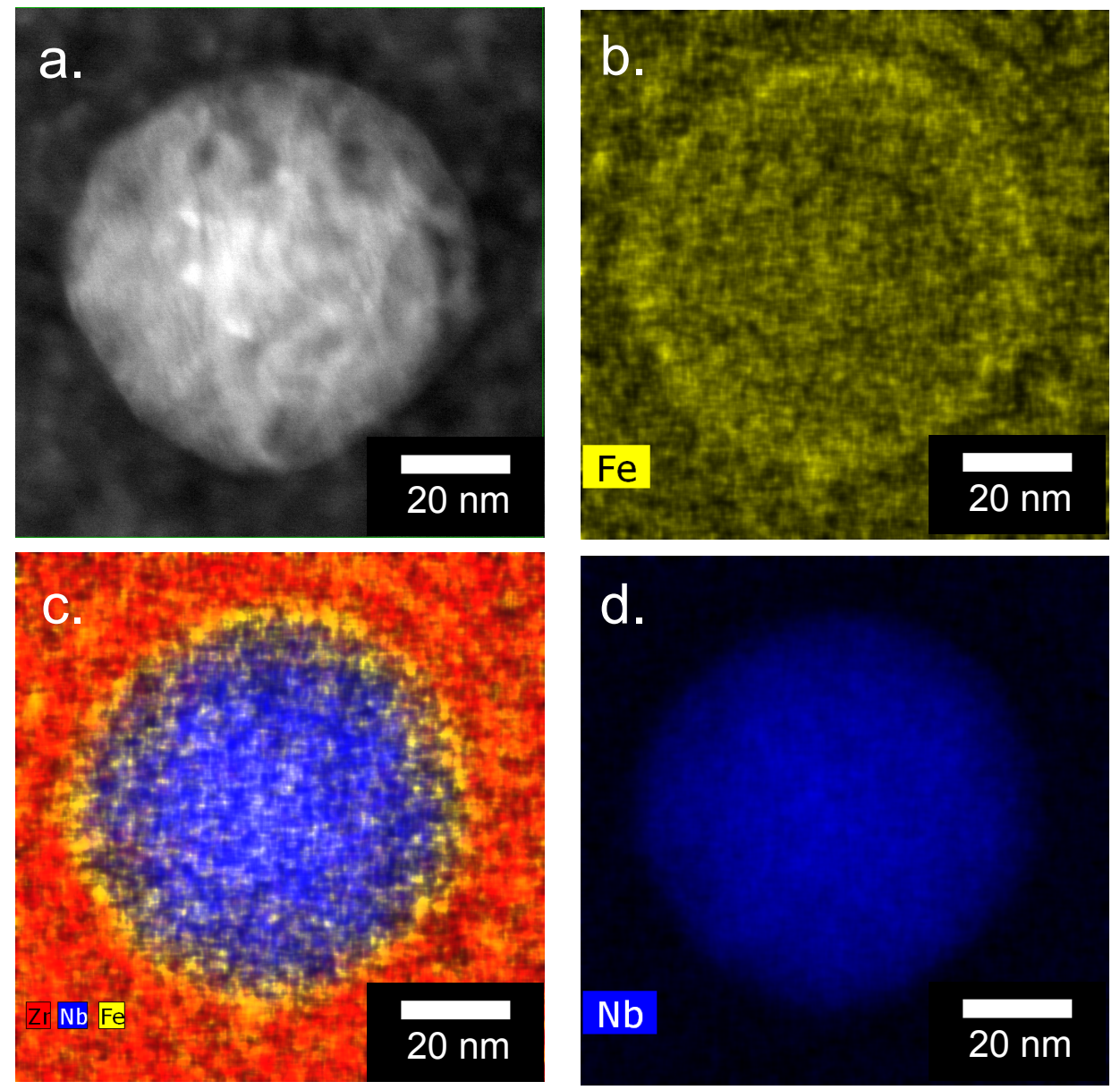

Figure 4: EDX spectrum imaging of a Nb-SPP in Low Tin ZIRLO ${ }^{\mathrm{TM}}$ after neutron irradiation to $18 \mathrm{dpa}$. Iron segregation to the SPP boundary is greatly reduced to less than $1 \mathrm{wt}$. $\%$ a. HAADF image of a second phase particle showing the area for which the EDX spectrum image was acquired b-d. Elemental maps for the distribution of iron, zirconium and niobium. $\mathrm{c}$ is a composite map including all three elements. 

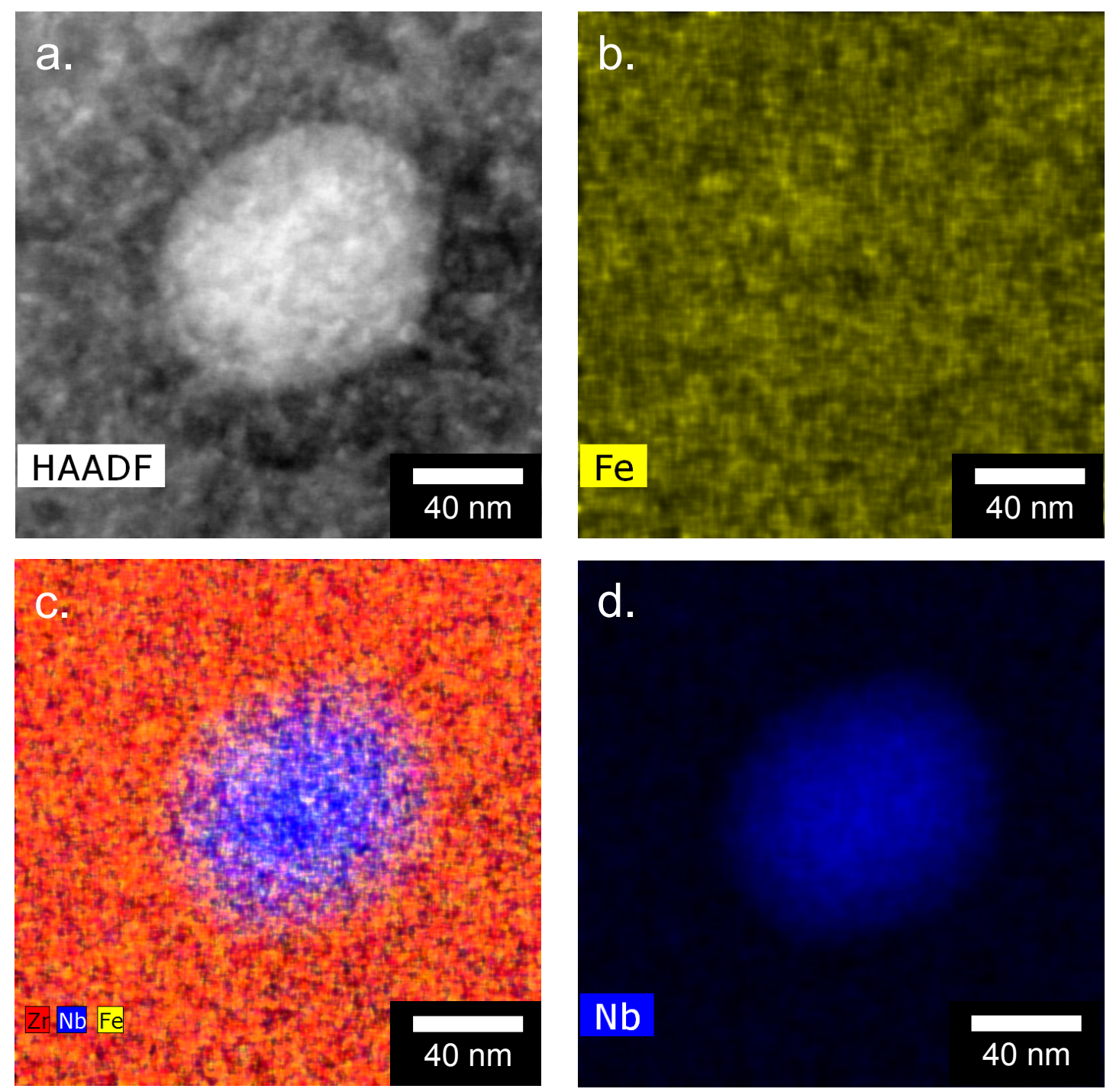

Figure 5: EDX spectrum imaging of a Nb-SPP in Low Tin ZIRLO ${ }^{\mathrm{TM}}$ after neutron irradiation to 18 dpa. Iron segregation to the SPP boundary is no longer observed a. HAADF image of a second phase particle showing the area for which the EDX spectrum image was acquired b-d. Elemental maps for the distribution of iron, zirconium and niobium. 

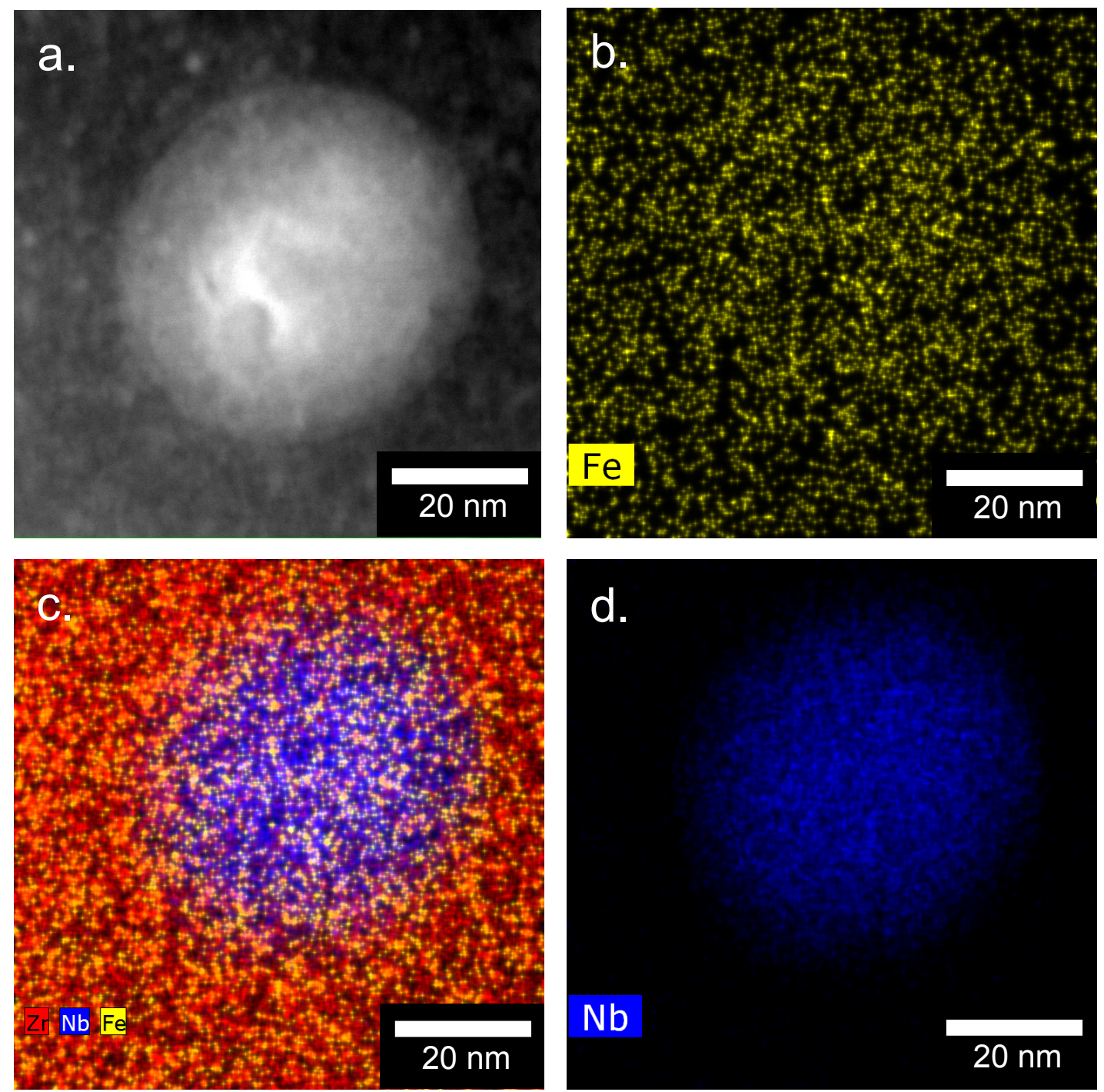

Figure 6: EDX spectrum imaging of a Nb-SPP in Low Sn ZIRLOTM after proton irradiation to 2.3dpa. No Fe enrichment was found on the particle boundary after proton irradiation. a. HAADF image of a second phase particle showing the area for which the EDX spectrum image was acquired b-d. Elemental maps for the distribution of iron, zirconium and niobium. 

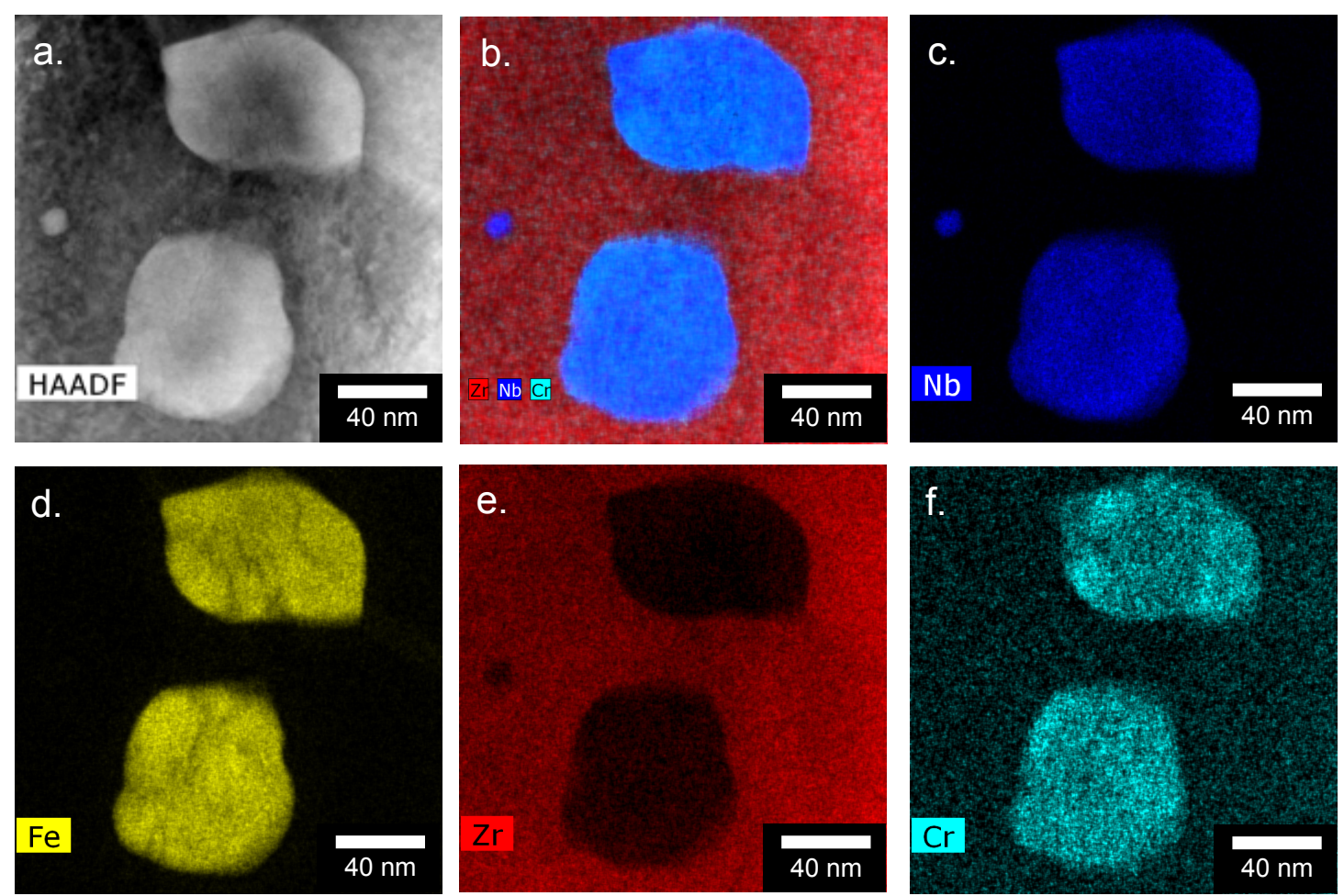

Figure 7: EDX spectrum imaging of two Zr-Nb-Fe-SPPs in Low Sn ZIRLOTM prior to irradiation. No Fe enrichment is found on the interface of this type of particle. $\mathrm{Cr}$ is found in the particle even though it is not an intentional alloying addition. a. HAADF image and b-d. elemental maps for the distribution of niobium, iron, zirconium and chromium extracted from simultaneously acquired spectrum image. b. is a composite map showing zirconium, niobium and chromium in one image.
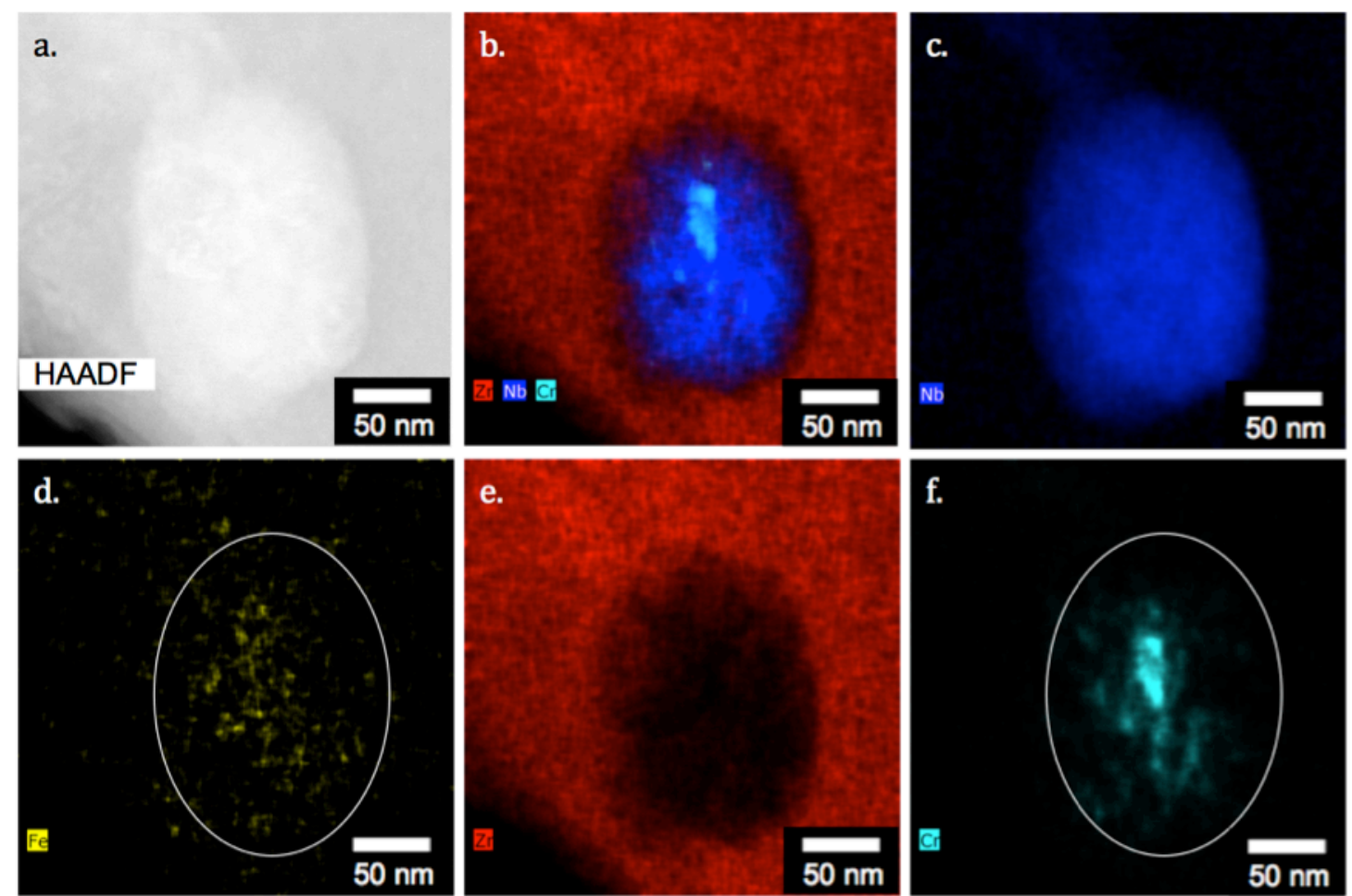
Figure 8: EDX spectrum imaging of a Zr-Nb-Fe-SPP after neutron irradiation to 18dpa. Typically, no $\mathrm{Fe}$ is detected in the particles in the neutron-irradiated material, whereas $\mathrm{Cr}$ is usually still found in the core of the SPP, often accumulated in small clusters as seen here. a. HAADF image and b-f. elemental maps for the distribution of niobium, iron, zirconium and chromium extracted from simultaneously acquired spectrum image. $b$ is a composite map showing niobium, chromium, and zirconium in a single image.

Cr Map from Spectral Image
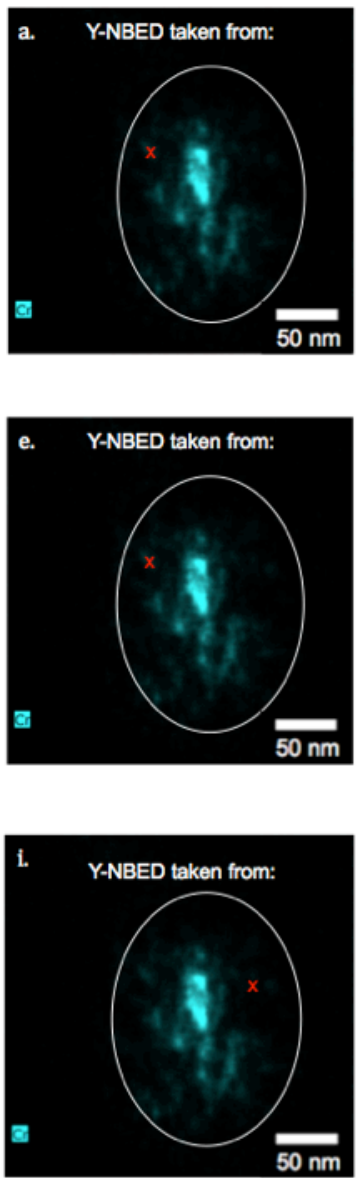

Y-NBED Pattern
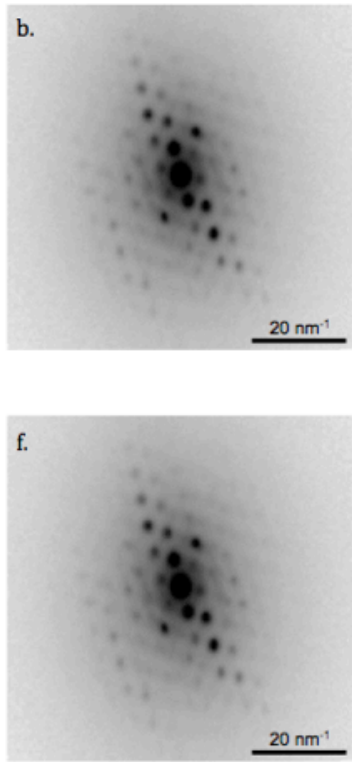

$\underline{20 \mathrm{~nm}^{-1}}$

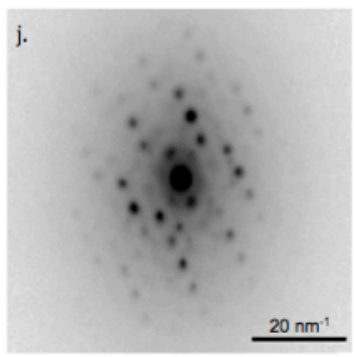

Index Map
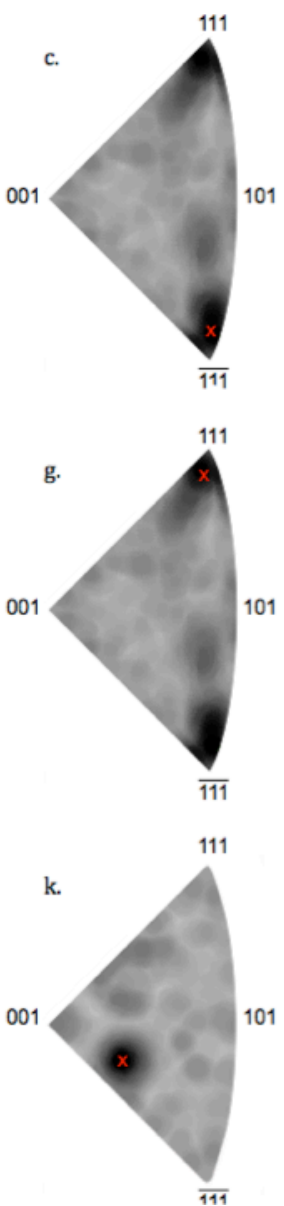

Plane Normal to Y-NBED Orientation

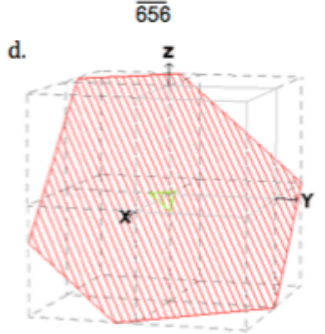

656

h.

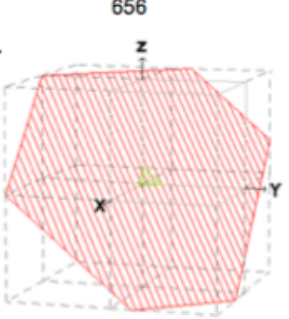

$\overline{216}$

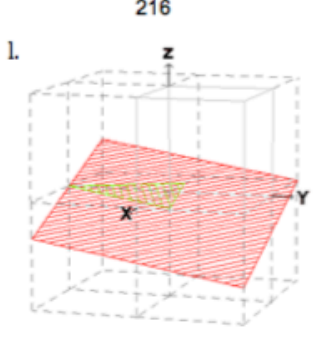

Figure 9: Phase and orientation indexing of the $\mathrm{Zr}-\mathrm{Nb}$-Fe(-Cr) SPP in Figure 7, neutron-irradiated to 18 dpa. The first column shows the where the precession nanobeam electron diffraction patterns (second column, Y-NBED) was taken from, marked with a red ' $x$ '. The third column shows the index map, which is a representative section of the spherical projection for the bcc $\beta$-Nb system, demonstrating that the Y-NBED has been indexed as $\beta$-Nb. The dark intensity represents in the index map represents the closest match to simulated patterns. The fourth column shows the plane normal to the indexed orientation. a-d. and e-f. show that the left hand size of the chromium core has two possible orientations, but that these are for the same axis; i-l. show that the right hand side has a single orientation, different from the left. The misorientation between the left and right hand sides is $33 \%$. 


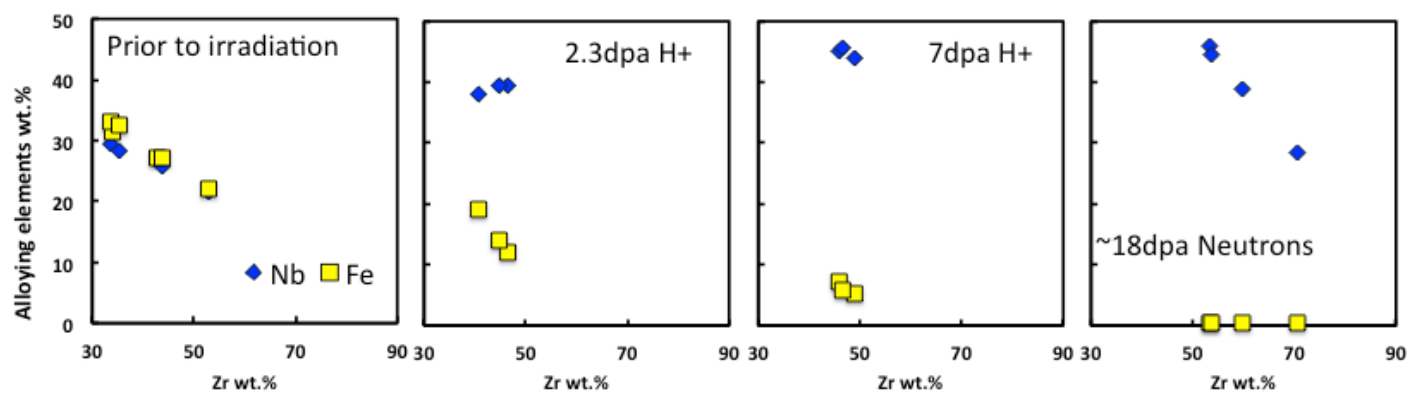

Figure 10: Composition of Zr-Nb-Fe-SPPs in Low Sn ZIRLOTM determined from the EDX spectrum images; a. prior to irradiation, b. after $2.3 \mathrm{~d}$ pa proton irradiation, c. after $7 \mathrm{dpa}$ proton irradiation, $\mathrm{d}$. after neutron irradiation to 18dpa.
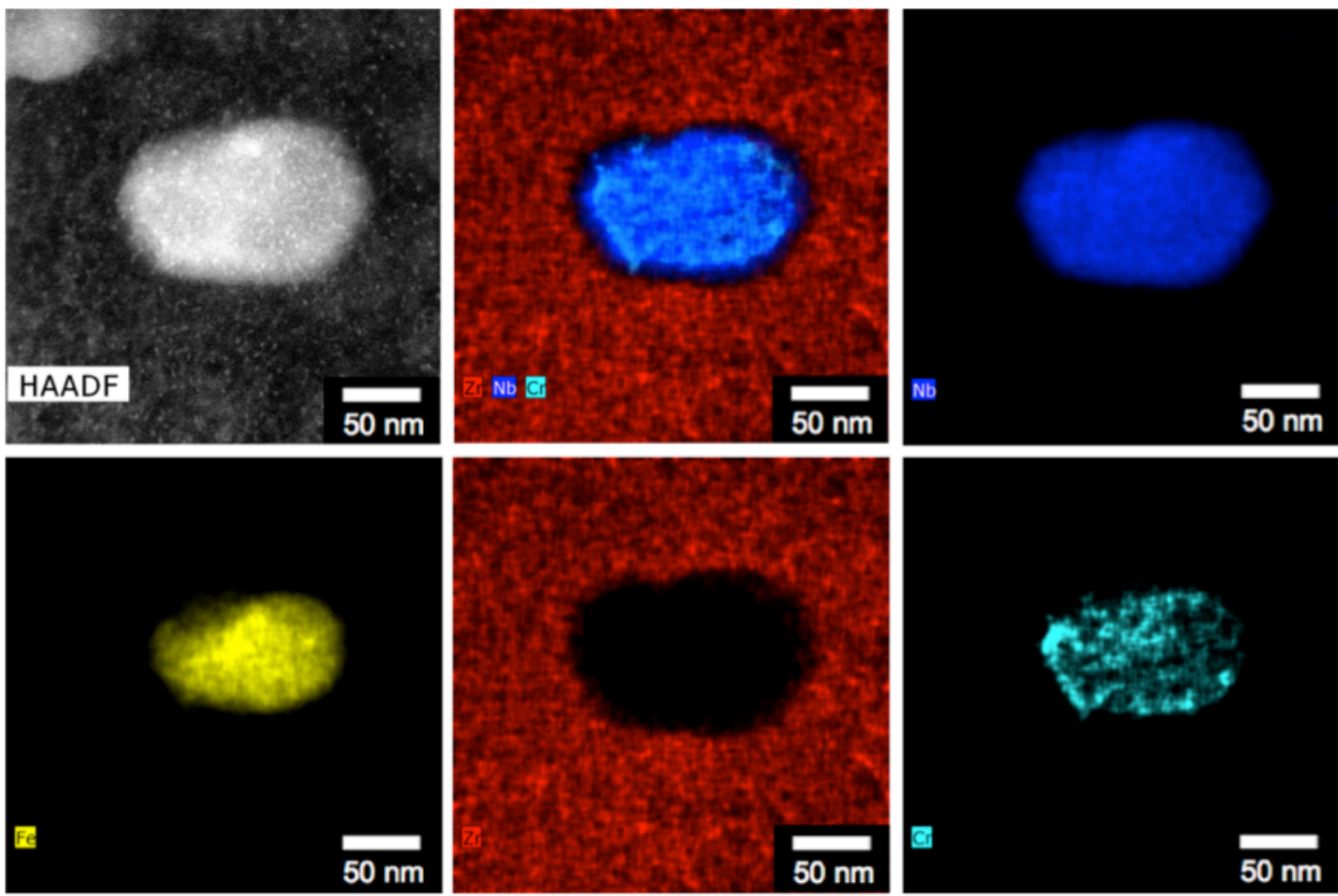

Figure 11: EDX spectrum imaging of a Zr-Nb-Fe-SPP after proton irradiation to 7 dpa. Fe is depleting from the edges of the particle and is only found in the core. chromium shows clustering and is spread thoughout the particle. a. HAADF image and b-f. elemental maps for the distribution of niobium, iron, zirconium and chromium extracted from simultaneously acquired spectrum image. $b$. is a composite image showing zirconium, niobium and chromium in a single image. 

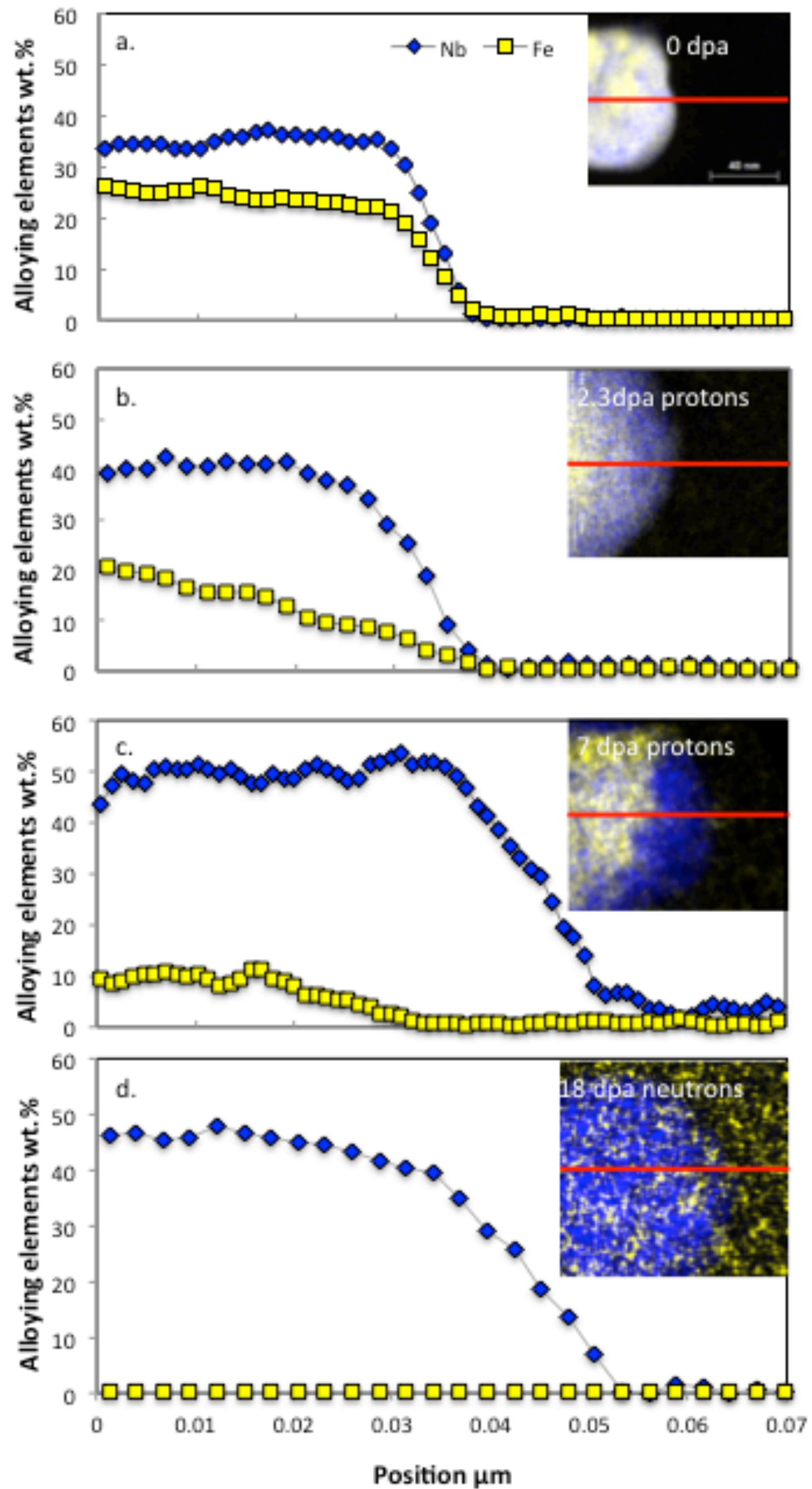
Figure 12: Line scans showing the change in $\mathrm{Nb}$ and Fe concentration from the centre of a $\mathrm{Zr}-\mathrm{Nb}-\mathrm{Fe}-$ SPP to the matrix; a. prior to irradiation, b. after 2.3 dpa proton irradiation, c. after 7 dpa proton irradiation, d. after 18dpa neutron irradiation.
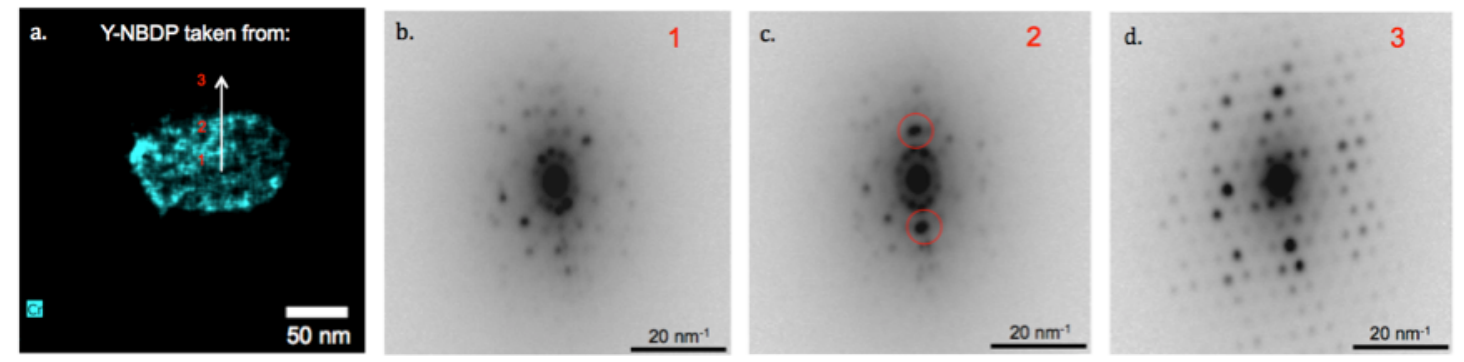

Figure 13: Precession nanobeam electron diffraction (Y-NBED) patterns from the Zr-Nb-Fe(-Cr) SPP in Figure 11, proton-irradiated to 7 dpa. a. shows the position that the Y-NBED pattern was taken from relative to the chromium elemental map; $b, c$ and d. show the Y-NBED patterns from areas 1, 2 and 3 , respectively. Area 1 is at the Fe-rich centre of the SPP, area 2 is from the Fe-depleted region of the SPP and area 3 is from the $\alpha-Z r$ matrix. Pattern c. shows extra spots in the Fe-depleted region, circled in red, giving an indication of a possible phase transformation in this area.

\section{References}

1. Sabol, G. P., Zirconium in the Nuclear Industry: 14th International Symposium; ASTM STP 1467, 2005; pp 3-24.

2. Sabol, G. P.; Kilp, G. R.; Balfour, M. G.; Roberts, E., Zirconium in the Nuclear Industry: 8th International Symposium; ASTM STP 1023, 1989; pp 227244.

3. $\quad$ Griffiths, M., Journal of Nuclear Materials 1988, 159 (0), 190-218.

4. $\quad$ Yang, W. J. S.; Tucker, R. P.; Cheng, B.; Adamson, R. B., Journal of Nuclear Materials 1986, 138 (2-3), 185-195.

5. Griffiths, M.; Gilbert, R. W.; Carpenter, G. J. C., Journal of Nuclear Materials 1987, 150 (1), 53-66.

6. Gilbon, D.; Simonot, C., Zirconium in the Nuclear Industry: 10th International Symposium; ASTM STP 1245, 1994; pp 521-548.

7. Adamson, R. B., Zirconium in the Nuclear Industry: 12th International Symposium, ASTM STP 1354, 2000, pp 15-31.

8. Griffiths, M. in: Zirconium in the Nuclear Industry: 15th International Symposium, ASTM STP 1505 2009, 19-26.

9. De Carlan, Y.; Regnard, C.; Griffiths, M.; Gilbon, D.; Lemaignan, C. in: Zirconium in the Nuclear Industry: 11th International Symposium, ASTM STP 1295, 1996; pp 638-653.

10. Griffiths, M.; Gilbert, R. W., Journal of Nuclear Materials 1987, 150 (2), 169-181.

11. Yueh, H. K.; Kesterson, R. L.; Comstock, R. J.; Shah, H. H.; Colburn, D. J.; Dahlback, M.; Hallstadius, L. in: Zirconium in the Nuclear Industry: 14th International Symposium; ASTM STP 1467, 2005; pp 330-346.

12. Was, G. S.; Busby, J. T.; Allen, T.; Kenik, E. A.; Jensson, A.; Bruemmer, S. M.; Gan, J.; Edwards, A. D.; Scott, P. M.; Andreson, P. L., Journal of Nuclear Materials 2002, 300 (2-3), 198-216. 
13. Was, G. S.; Allen, T. R.; Busby, J. T.; Gan, J.; Damcott, D.; Carter, D.; Atzmon, M.; Kenik, E. A., Journal of Nuclear Materials 1999, 270 (1-2), 96-114.

14. Cann, C. D.; So, C. B.; Styles, R. C.; Coleman, C. E., Journal of Nuclear Materials 1993, 205 (0), 267-272.

15. Chapman, O. J. V.; McElroy, R. J.; Sheldon, E. E. in: Zirconium in the Nuclear Industry: 6th International Symposium, ASTM STP 824, 1984; pp 343375.

16. Tournadre, L.; Onimus, F.; Béchade, J. L.; Gilbon, D.; Cloué, J. M.; Mardon, J. P.; Feaugas, X.; Toader, O.; Bachelet, C., Journal of Nuclear Materials 2012, 425 (1-3), 76-82.

17. Zu, X. T.; Sun, K.; Atzmon, M.; Wang, L. M.; You, L. P.; Wan, F. R.; Busby, J. T.; Was, G. S.; Adamson, R. B., Philosophical Magazine 2005, 85 (4-7), 649659.

18. Foster, J. P.; Yueh, H. K.; Comstock, R. J., Zirconium in the Nuclear Industry: 15th International Symposium, ASTM STP 1505 2009, pp 45769.

19. Fidleris, V., Tucker, R. P., \& Adamson, R. B., Zirconium in the Nuclear Industry: Seventh International Symposium, ASTM STP 939 1987, 49-85.

20. Griffiths, M., Gilbert, R. W., \& Carpenter, G. J. C., 1987, J. Nucl. Mater., 150, 53-66

21. Waterside corrosion of zirconium alloy in nuclear power plants, IAEATECDOC-966, 1998, 199.

22. Bragg-Sitton, S. M., Advanced LWR Nuclear Fuel Cladding System Development Technical Program Plan, 2012, INL, Idaho Falls, ID 83415.

23. Was, G. S., Fundamentals of Radiation Materials Science. Springer: Berlin Heidelberg New York, 2007; p 83.

24. Stoller, R. E.; Toloczko, M. B.; Was, G. S.; Certain, A. G.; Dwaraknath, S.; Garner, F. A., Nuclear Instruments and Methods in Physics Research Section B: Beam Interactions with Materials and Atoms 2013, 310 (0), 7580.

25. Hengstler-Eger, R. M.; Baldo, P.; Beck, L.; Dorner, J.; Ertl, K.; Hoffmann, P. B.; Hugenschmidt, C.; Kirk, M. A.; Petry, W.; Pikart, P.; Rempel, A., Journal of Nuclear Materials 2012, 423 (1-3), 170-182.

26. Genc, A.; Kovarik, L.; Gu, M.; Cheng, H.; Plachinda, P.; Pullan, L.; Freitag, B.; Wang, C., Ultramicroscopy 2013, 131 (0), 24-32.

27. Rauch, E. F., \& Dupy, L., 2005, Arch. Metall. Mater., 50(1), 87-99.

28. Vincent, R., \& Midgley, P. A., 1994, Ultramicroscopy, 53, 271-282.

29. Rauch, E. F., Véron, M., Portillo, J., Bultreys, D., Maniette, Y., \& Nicolopoulos, S., 2008, Microsc. Anal., 22(6), S5-S8.

30. Garner, A., Gholinia, A., Frankel, P., Gass, M., MacLaren, I., \& Preuss, M., 2014, Acta Mater. (accepted).

31. Lemaignan, C.; Motta, A. T., Zirconium Alloys in Nuclear Applications. In Nuclear Materials, Cahn, R. W.; Haasen, P.; Kramer, E. J., Eds. VCH: New York, 1994; pp 1-51.

32. Sabol, G. P.; Comstock, R. J.; Weiner, R. A.; Larouere, P.; Stanutz, R. N., Zirconium in the Nuclear Industry: 10th International Symposium; ASTM STP 1245, 1994; pp 724-744.

33. Shishov, V. N., Peregud, M. M., Nikulina, A. V, Kobylyansky, G. P., \& Ostrovsky, Z. E., 2005, J. ASTM Int., 2(8) 666-685. 
34. Motta, A. T.; Lefebvre, F.; Lemaignan, C., Zirconium in the Nuclear Industry: 9th International Symposium; ASTM STP 1132, 1991; pp 718739.

35. Valizadeh, S.; Ledergerber, G.; Abolhassani, S.; Jädernas, D.; Dahlback, M.; Mader, E. V.; Zhou, G.; Wright, J.; Hallstadius, L., Zirconium in the Nuclear Industry: 16th International Symposium, ASTM STP 1529, 2012, 729-753.

36. Shishov, V. N.; Nikulina, A. V.; Markelov, V. A.; Peregud, M. M.; Kozlov, A.; Averin, S. A.; Kolbenkov, S. A.; Novoselov, A. E., Zirconium in the Nuclear Industry: 11th International Symposium, ASTM STP 1295, 1996; pp 603622.

37. Shishov, V. N.; Peregud, M. M.; Nikulina, A. V.; Shebaldov, P. V.; Tselischev, A. V.; Novoselov, A. E.; Kobylyansky, G. P.; Ostrovsky, Z. E.; Shamardin, V. K., Zirconium in the Nuclear Industry: 13th International Symposium, ASTM STP 1423, 2002; pp 758-779.

38. Griffiths, M.; Mecke, J. F.; Winegar, J. E., Zirconium in the Nuclear Industry: 11th International Symposium, 1996; pp 580-602.

39. Cox, B., Journal of Nuclear Materials 2005, 336 (2-3), 331-368.

40. Huang, P. Y.; Mahmood, S. T.; Adamson, R. B., Zirconium in the Nuclear Industry: 11th International Symposium, ASTM STP 1295, 1996; pp 726757.

41. Griffiths, M.; Holt, R. A.; Rogerson, A., Journal of Nuclear Materials 1995, 225 (0), 245-258.

42. Mahmood, S. T.; Farkas, D. M.; Adamson, R. B.; Etoh, Y., Zirconium in the Nuclear Industry: 12th International Symposium, ASTM STP 1354, 2000; Vol. 1354, pp 139-169.

43. Hayashi, H.; Hashimoto, N.; Ohnuki, S., Journal of Nuclear Materials 2013, 442 (1-3, Supplement 1), S830-S833.

44. $\quad$ King, S. J.; Kesterson, R. L.; Yueh, H. K.; Comstock, R. J.; Herwig, W. M.; Ferguson, S. D., Zirconium in the Nuclear Industry: 13th International Symposium, ASTM STP 1423, 2002; pp 471-489.

45. Griffiths, M.; Gilbon, D.; Regnard, C.; Lemaignan, C., Journal of Nuclear Materials 1993, 205 (0), 273-283.

46. Ivermark, M.; Robson, J.; Preuss, M. in: Zirconium in the Nuclear Industry: 16th International Symposium, ASTM STP 1529, 2012, 150-175.

47. Ivermark, M. PhD thesis: Characterisation of the Matrix Chemistry in Zirconium Alloys. The University of Manchester, 2009.

48. King, A.D.; Hood, G.M. Holt, Journal of Nuclear Materials 185, 1991. 174181. 